\title{
AMPLIFICAÇÃO DO CONCEITO DE PROVA COMO COROLÁRIO AO PRINCÍPIO DO CONTRADITÓRIO: REVISITANDO A SÚMULA No 7 DO SUPERIOR TRIBUNAL DE JUSTIÇA
}

\author{
AMPLIFICATION OF THE CONCEPT OF PROOF AS COROLLARY TO THE \\ PRINCIPLE OF THE CONTRADICTORY: REVISITING THE SUMMULA \\ NUMBER \#7 OF THE SUPREME COURT
}

\section{Vitor Augusto Gaioski Pagani ${ }^{1}$ Caio Cezar Bellotto ${ }^{2}$}

SUMÁRIO: Introdução; 1 Concepção de Prova Como Matéria Processual e As Implicações No Contraditório; 2 A Barreira da Súmula 7 do STJ; Considerações Finais; Referências das Fontes Citadas.

\section{RESUMO}

Através do presente trabalho, busca-se fomentar a discussão acerca dos limites do conceito de prova, e sua consequente classificação como matéria de ordem processual, principalmente tido como matéria apta a gerar incomensuráveis efeitos no princípio do contraditório. Em vista desta substancial alteração havida no decorrer da instrução processual, motivo este que, seguramente, acabará por trazer uma modificação no entendimento da Súmula no 7 , do Superior de Tribunal de Justiça, passase a uma rápida análise sobre a jurisprudência formadora desta súmula e a distinção entre regras de instrução e regras de julgamento. De igual forma, será demonstrado que, mesmo a despeito de, em um primeiro momento, toda a questão relativa a prova seja afastada da análise do Recurso Extraordinário, algumas vezes não está-se diante de fatos, mas, sim, da qualificação jurídica dos fatos.

\footnotetext{
${ }^{1}$ Acadêmico do Mestrado em Direito Processual e Cidadania da Universidade Paranaense - UNIPAR.

2 Mestre em Direito Processual e Cidadania da Universidade Paranaense - UNIPAR.
} 
PAGANI, Vitor Augusto Gaioski e BELLOTTO, Caio Cezar. Amplificação do conceito de prova como corolário ao princípio do contraditório: revisitando a súmula no 7 do superior tribunal de justiça. Revista Eletrônica Direito e Política, Programa de Pós-Graduação Stricto Sensu em Ciência Jurídica da UNIVALI, Itajaí, v.10, n.3, 2ㅇ quadrimestre de 2015. Disponível em: www.univali.br/direitoepolitica ISSN 1980-7791.

PALAVRAS-CHAVE: Prova; Princípio do Contraditório; Súmula no 7 do Superior Tribunal de Justiça.

\section{ABSTRACT}

By means of this piece of work, we seek to incite the discussion around the concepts of proof, and its consequent classification a matter of processual order, mainly had as matter apt to generate immeasurable effects on the contradiction principle. With an eye on this substantial alteration made during the processual instruction, reason that, safely, will end up bringing a change in the understanding of the Summula number \#7, of the Supreme Court, we pass on to a quick analysis on the jurisprudence which made this summula, and the distinction between instruction and judgment rules. Likewise, we will demonstrate that, even in spite of, in a first moment, all questions related to proof being driven from the analysis of the Extraordinary Appeal, sometimes one is not before the facts, but the juridical qualification of the facts instead.

KEYWORDS: Proof; Principles of Contradiction; Summula number \#7 of the Supreme Court.

\section{INTRODUÇÃO}

Há muito se discute na doutrina jurídica pátria, se o conceito de prova encontrar-se-ia filiado ao direito material ou ao direito processual, principalmente em vista de que tanto o Código Civil Brasileiro, quanto o Código de Processo Civil Brasileiro, tratam de modo pormenorizado sobre o tema.

Muito diriam que a concepção do conceito de prova seria muito mais uma questão meramente acadêmica do que prática, pois que, em um primeiro enfoque, estas discussões trariam pouco, senão, nenhum, efeito no dia-adia dos tribunais.

Todavia, por intermédio do presente estudo se busca modificar este entendimento, de modo que procura-se revelar o conceito de prova como 
PAGANI, Vitor Augusto Gaioski e BELLOTTO, Caio Cezar. Amplificação do conceito de prova como corolário ao princípio do contraditório: revisitando a súmula no 7 do superior tribunal de justiça. Revista Eletrônica Direito e Política, Programa de Pós-Graduação Stricto Sensu em Ciência Jurídica da UNIVALI, Itajaí, v.10, n.3, 2ㅇ quadrimestre de 2015. Disponível em: www.univali.br/direitoepolitica ISSN 1980-7791.

filiado com critério de direito processual, uma vez que, na subjetividade do caso, a mesma irá determinar abrangentes modificações no formato da instrução da lide.

Nesta senda, pode-se reconhecer, igualmente, que se a instrução processual sofrerá modificações deveras relevantes, por via de consequência, haverá substanciais implicações no princípio do contraditório, vez que o mesmo, de acordo com o que veremos, acabará demonstrando-se como resultante de uma instrução efetiva, apta a gerenciar paridade entre os pólos litigantes.

Por fim, pretende-se vislumbrar quais as implicações práticas que esta relativização no modelo probatório clássico traz em um confronto direto contra a Súmula no 7, do Superior Tribunal de Justiça. Irá verificar-se desde o momento da concepção desta famigerada súmula, com suas respectivas "decisões-criadoras", e a consentânea modificação do caráter probatório que implicou uma modulação de seus efeitos.

Para tanto, procura-se realizar uma rápido apanhado de como o Superior Tribunal de Justiça tem vislumbrado as regras e de instrução e, de outra ponta, as regras de julgamento, sob um olhar, outrossim, focado na Teoria da Qualificação Jurídica dos Fatos.

\section{CONCEPÇÃo de PROVA COMO MATÉRIA PROCESSUAL E AS IMPLICAÇÕES NO CONTRADITÓRIO}

Parando para pensar, de fato, nos parece um pouco contraditório, como bem frisa Wendel de Brito Lemos Teixeira ${ }^{3}$, que a matéria probatória seja

\footnotetext{
3 TEIXEIRA, W. d. B. L. A Natureza Jurídica das Normas sobre Provas. Revista Jurídica: órgão nacional de doutrina, jurisprudência, legislação e crítica judiciária. Ano 61, no 430, Agosto, 2013. P. 15.
} 
PAGANI, Vitor Augusto Gaioski e BELLOTTO, Caio Cezar. Amplificação do conceito de prova como corolário ao princípio do contraditório: revisitando a súmula no 7 do superior tribunal de justiça. Revista Eletrônica Direito e Política, Programa de Pós-Graduação Stricto Sensu em Ciência Jurídica da UNIVALI, Itajaí, v.10, n.3, 2ㅇ quadrimestre de 2015. Disponível em: www.univali.br/direitoepolitica ISSN 1980-7791.

trazida de forma normatizada tanto no âmbito do Código Civil, como, outrossim, no corpo do Código de Processo Civil.

Mais do que enfrentar o campo da validade e da eficácia da prova, principalmente no sentido de perquirir o início de seus efeitos jurídicos diante da validade de uma normal de caráter material, ou mesmo, processual, é certo que entender a prova na concepção do processo civil sob um novo prisma (caráter eminentemente processual), possui em seu bojo uma grande relevância técnica diante do enfrentamento de temas que são óbices ao encontro do devido processo legal.

À partir desta constatação, vale a pena, sem dúvida, dedicarmos um tempo para o magistério do professor Rui Manuel de Freitas Rangel, que, incorporando a trajetória da doutrina portuguesa sobre este tema, muito tem a nos acrescentar.

[...] A maioria da doutrina entende que as regras de direito probatório são de direito processual.

o direito probatório é direito processual o que se explica se atendermos ao facto da prova forma a convicção do juiz dentro do processo. Cabe ao direito processual regulá-la em toda a sua extensão.

Os representantes desta tese que atribui natureza processual às regras (gerais e especiais) sobre o ónus da prova são, entre outros, Bentham, Micheli, Chiovenda, Liebman, Silva Melero e Miguel y Alonso.

A justificação deste entendimento é, de um modo geral, o mesmo que é sustentado por Manuel de Andrade e José Alberto dos Reis: as regras sobre o ónus da prova limitam diretamente a decisão que o juiz há-de toma, pelo que o seu lugar é direito processual.

Atribuir um caracter unicamente substantivo seria confundir a sua incidência substantiva com a sua natureza e desprezar a sua profunda relevância no processo. $[\ldots]^{4}$

Mesmo que este trabalho não possua como fito o estudo aprofundado quanto à natureza jurídica da prova, é relevante ponderar que

\footnotetext{
${ }^{4}$ RANGEL, R. M. d. F. O ónus da prova no processo civil. Coimbra, Almedina. 2006. P. 209.
} 
PAGANI, Vitor Augusto Gaioski e BELLOTTO, Caio Cezar. Amplificação do conceito de prova como corolário ao princípio do contraditório: revisitando a súmula no 7 do superior tribunal de justiça. Revista Eletrônica Direito e Política, Programa de Pós-Graduação Stricto Sensu em Ciência Jurídica da UNIVALI, Itajaí, v.10, n.3, 2ㅇ quadrimestre de 2015. Disponível em: www.univali.br/direitoepolitica ISSN 1980-7791.

doutrinadores de renome tem afirmado que as normas que pautam sobre prova têm natureza unicamente de cunho processual.

Nesta dicção, como forma de alertar à mutação que aos poucos vem se estabelecendo neste novel formato processual civil, cabem as palavras da professora Gisele Leite, sobre tema, igualmente, caro à análise da modernidade do direito processual civil.

[...] A ciência processual moderna repudia (e com razão) a falsa ideia de um processo civil do autor. Assim como não mais é condizente o processo civil guiado apenas pela regra de que $a b$ initio competem as partes em busca de fontes de prova e a iniciativa de incluí-las na instrução processual, não cabendo ao juiz senão recebe-las, processar os meios de prova segundo os procedimento que a lei estabelece e, afinal, levar em conta os resultados, ao julgar.

É, sem dúvida, ultrapassado o processo civil, dispositivo clássico que tinha um juiz estático e receptivo, sem outra missão no procedimento senão de ser gestor e ordenador, quando necessário. A visão tradicional do processo civil que dá excepcional interesse às partes atuando cada qual segundo seu próprio desejo de fazer prevalecer suas razões e seus alegados direitos e sobre essa premissa apoia-se a legitimidade do comportamento puramente passivo do juiz quando estas se omite. $[\ldots]^{5}$

Sob este enfoque, pautamos a discutir, pois, que, tratar de prova, nem sempre é sinônimo de tratar de fatos. Evidencia-se, em um primeiro momento, por uma questão de costume na análise deste tema, que tratar de prova é sempre relatar as questões dos fatos ocorridas antes da formação da lide, que sequencialmente restarão havidos no âmbito da marcha processual. Certamente, a prova pode ser analisada sob outro aspecto, qual seja, o modo pelo qual as partes litigantes chegaram a compor o objeto jurídico em litígio.

Esta função observadora de que o objeto em litígio é muito menor do que toda a gama de fatores que permeiam o bem jurídico tutelado, há algum tempo, ganhou força no aspecto da atenção dos doutrinadores em relação

${ }^{5}$ LEITE, G. Apontamentos sobre a Teoria Geral da Prova. Revista Síntese Direito Civil e Processual Civil. v.12, n.84, jul/ago. 2013. P. 74. 
PAGANI, Vitor Augusto Gaioski e BELLOTTO, Caio Cezar. Amplificação do conceito de prova como corolário ao princípio do contraditório: revisitando a súmula no 7 do superior tribunal de justiça. Revista Eletrônica Direito e Política, Programa de Pós-Graduação Stricto Sensu em Ciência Jurídica da UNIVALI, Itajaí, v.10, n.3, 2ㅇ quadrimestre de 2015. Disponível em: www.univali.br/direitoepolitica ISSN 1980-7791.

à(s) vulnerabilidade existentes entre os litigantes. Por isto, sabendo-se que tratar os litigantes na medida de suas diversidades implica em reconhecer que os fatos que tentarão serem doravante reproduzidos mediante uma(algumas) prova(s), possuem aspectos mais subjetivos, servem como supedâneo à admitirmos que os fatos, em si, não servem a dar azo à formação da prova, mas, em verdade, todo este contexto etéreo, predecessor ao acontecimento dos fatos.

A reprodução dos fatos por intermédio de um meio de prova, sob este prisma, calharia em uma constatação ainda mais perigosa para este fim, que o contraditório não seria enfocado, conforme afirma João Bosco Maciel Junior, nas formas mais corriqueiras do modo de pensar a prova.

[...] Em linhas gerais, e sem aprofundamento no tema vertente, "prova" pode ser entendida em três aspectos: primeiro, como os meios pelos quais o interessado pode servir-se para demonstração do thema probandum; segundo, como procedimento probatório; e terceiro, como o resultado do procedimento probatório mencionado. $[\ldots]^{6}$

Corroborando o supramencionado, é de bom alvitre ponderar os ensinamentos de Francisco Rosito, os quais, por sua vez, são fortemente influenciados nos estudos do direito probatório, pela doutrina italiana, conforme se verá a seguir.

[...] De um modo geral, a doutrina apenas examina a questão sob o terceiro enfoque apresentado por Michele Taruffo, isto é, sobre os aspectos diferentes do fenômeno probatório, reduzindo a noção a três significados: $1^{\circ}$ ) a primeira acepção de prova designa os "meios de prova", através dos quais pode servir para demonstração do thema probandum, ou seja, os documentos, as testemunhas, inspeção judicial, etc.; $2^{\circ}$ ) a segunda acepção de prova designa o procedimento probatório, ou seja, o complexo da atividade regulada pela lei, através do qual o juiz e as partes obtêm os meios de prova ao processo; $3^{\circ}$ ) a terceira acepção de prova designa o resultado do procedimento probatório, isto é, o

6 MACIEL JUNIOR, J. B. Aplicabilidade do princípio do contraditório nas relações particulares. São Paulo. Saraiva, 2009. P. 74. 
PAGANI, Vitor Augusto Gaioski e BELLOTTO, Caio Cezar. Amplificação do conceito de prova como corolário ao princípio do contraditório: revisitando a súmula no 7 do superior tribunal de justiça. Revista Eletrônica Direito e Política, Programa de Pós-Graduação Stricto Sensu em Ciência Jurídica da UNIVALI, Itajaí, v.10, n.3, 2o quadrimestre de 2015. Disponível em: www.univali.br/direitoepolitica ISSN 1980-7791.

convencimento ao qual o juiz chega através dos meios de prova. $[\ldots]^{7}$

Importante registrar aqui, que toda esta modificação, indubitavelmente, trouxe, nos ensinamentos de Fazzalari $^{8}$, a necessidade da jurisdição se fazer mais efetiva justamente no critério mais intangível da mesma, de maneira que, em seus dizeres, busca-se um [...] julgamento vinculado ao espaço técnico-procedimental-discursivo do processo cognitivo de direitos, como conclusão co-extensiva da argumentação das partes [...].

Ao enfrentar este tema, cremos que seja inerente entender que só se chegou a este patamar de se poder conceber o direito processual civil como fruto de algumas escolhas indiretas em razão ao bem tutelado pelo processo, mediante a concepção da constitucionalização do direito, conforme bem adverte Virgílio Afonso da Silva ${ }^{9}$.

Neste espeque, resta digno de censura não tocar no tema dos princípios processuais, sendo um, em especial, o do contraditório, garantindo ainda uma maior amplificação dos conceitos trazidos pela Magna Carta. Esta temática de valores com fulcro nos princípios jurídicos, encontra grande espaço no Novo Código de Processo Civil, o qual adentra, indubitavelmente, em um conceito de neoconstitucionalismo, culminando, pois, para o chamado neoprocessualismo.

Sobre este assunto, a palavra de autoridade é do professor Eduardo Cambi,

[...]Conclui-se que a melhor medida possível (ou seja, o que vem a ser um comando de otimização) depende da argumentação jurídica a ser desenvolvida nos casos concretos. Está-se diante de uma dimensão de peso (isto é, qual o argumento que, estando em

\footnotetext{
7 ROSITO, F. Direito probatório: as máximas de experiência em juízo. Porto Alegre. Livraria do Advogado, 2007. P. 26.

${ }^{8}$ FAZZALARI, E. Instituições de Direito Processual. trad. Elaine Nassif. Campinas: Bookseller, 2006. P. 62.

${ }^{9}$ SILVA, V. A. d. A constitucionalização do direito: os direitos fundamentais nas relações entre particulares. São Paulo. Malheiros, 2005. P. 149.
} 
PAGANI, Vitor Augusto Gaioski e BELLOTTO, Caio Cezar. Amplificação do conceito de prova como corolário ao princípio do contraditório: revisitando a súmula no 7 do superior tribunal de justiça. Revista Eletrônica Direito e Política, Programa de Pós-Graduação Stricto Sensu em Ciência Jurídica da UNIVALI, Itajaí, v.10, n.3, 2ㅇ quadrimestre de 2015. Disponível em: www.univali.br/direitoepolitica ISSN 1980-7791.

conflito, deve prevalecer) e, por isto, as possibilidades (fáticas e jurídicas) de aplicação do princípio podem ser desenvolvidas a partir da máximas de proporcionalidade (adequação, exigibilidade e proporcionalidade e sentido estrito) $[\ldots]^{10}$

Em sequência, um espírito unificado entre o contraditório e esta nova jaez denominada de neoprocessualismo, sobejamente influenciado por tratar de prova como elemento tipicamente processual, de forma a abandonar as velhas formulações expressas de prova no sentido de reprodução apenas de matérias de fato, permitem refletir que um contraditório efetivo, sem dúvida, é um revérbero imanente da condição instrutória de que a lide revela.

Observe-se que conforme Maria Elizabeth de Castro Lopes ${ }^{11}$ bem ressalta, a importância da aplicação deste princípio no bojo da produção de provas é deveras curial, e, nesta senda, permite-nos entender que um ensejo refletiria em outro, haja vista que, se de um lado a produção de provas é restrita diante de um contraditório ineficaz (eis que pode ser demasiadamente cadenciada, abandonando, com efeito, o verdadeiro objetivo da Carta Política no aspecto de constitucionalizar o direito), podemos entender que nesta mesma linha, aplica-se um déficit na contemplação de uma decisão que aproxima-se do critério, quase utópico, conhecido como justiça.

Mesmo a despeito de sabermos que o critério de justiça seja, na mais otimista das acepções, verdadeiramente intangível, é inconcebível não admitir que está-se sempre a buscar tal conceito. Por isto, a prova deve ser analisada sob o condão de uma formulação subjetiva entre os litigantes. Toda esta subjetividade estará vinculada ao modo de encarar o

10 CAMBI, E.. Neoconstitucionalismo e neoprocessualismo: direitos fundamentais, políticas públicas e protagonismo judiciário. 2. ed. São Paulo. Revista dos Tribunais, 2011. P. 99.

11 LOPES, M. E. d. C.. Princípios processuais civis na Constituição. coord: Maria Elizabeth de Castro Lopes e Olavo de Oliveira Neto. Rio de Janeiro. Elsevier, 2008. P. 101. 
PAGANI, Vitor Augusto Gaioski e BELLOTTO, Caio Cezar. Amplificação do conceito de prova como corolário ao princípio do contraditório: revisitando a súmula no 7 do superior tribunal de justiça. Revista Eletrônica Direito e Política, Programa de Pós-Graduação Stricto Sensu em Ciência Jurídica da UNIVALI, Itajaí, v.10, n.3, 2ㅇ quadrimestre de 2015. Disponível em: www.univali.br/direitoepolitica ISSN 1980-7791.

processo e, destarte, o modelo de prova não escapa deste formato. Em vista disto, Ada P. Grinover expõe que:

[...] O processo deve ser visto na total aderência à realidade sociopolítica a que se destina, para o integral cumprimento da sua vocação primordial, que é a efetiva a atuação dos direitos materiais. Assim, todo o sistema processual passa a ser considerado como instrumento indispensável para atingir os escopos políticos, sociais e jurídicos da jurisdição; e a técnica processual como meio para a obtenção de cada um desses objetivos. $[\ldots]^{12}$

Ao mencionar tal formulação subjetiva, é de bom alvedrio delimitar que o modelo de prova deve ser modulado sob a ótica dos efeitos da produção instrutória que melhor poderá adequá-la à uma decisão jurisdicional, na medida do possível, tida como justa. À este respeito, cremos que uma decisão apenas será concebida como justa no momento em que atender a devida fundamentação enfatizada em instrução probatória adequada.

Abandonando-se os velhos paradigmas, abandona-se, outrossim, o conceito de o magistrado como mero espectador do processo, onde pouco, ou quase nada, possuía protagonismo, vez que, no Estado Democrático de Direito, a figura do juiz, como já bem previa o ilustre Pontes de Miranda, não representa o Estado, mas, sim, presenta o próprio Estado, uma vez que "é" o próprio Estado.

Não se poder olvidar, contudo, que, tratando o tema desta forma, está-se, tecnicamente falando, admitindo uma conotação política do magistrado (Estado). A doutrina do ilustre Michele Taruffo $^{13}$, com muito acerto nos revela este patamar, que, em muitos casos, acaba sendo, com o perdão da palavra, mascarado, em virtude de um eterno animus de se procurar dissociar direito de política.

\footnotetext{
12 GRINOVER, A. P. O processo em evolução. 2. ed. Rio de Janeiro. Forense, 1998. P. 20-1.

13 TARUFFO, M. Processo civil comparado: ensaios. apres. org. e trad. Daniel Mitidiero. São Paulo. Marcial Pons, 2013. P. 61.
} 
PAGANI, Vitor Augusto Gaioski e BELLOTTO, Caio Cezar. Amplificação do conceito de prova como corolário ao princípio do contraditório: revisitando a súmula no 7 do superior tribunal de justiça. Revista Eletrônica Direito e Política, Programa de Pós-Graduação Stricto Sensu em Ciência Jurídica da UNIVALI, Itajaí, v.10, n.3, 2ㅇ quadrimestre de 2015. Disponível em: www.univali.br/direitoepolitica ISSN 1980-7791.

Parece-nos, ainda que, ampliar desmedidamente a forma instrutória, no sentido de permitir uma maior atuação do magistrado, ainda causa desconforto em parte da doutrina processualista. Assim, conforme assinalou Eduardo Chemale Selistre Peña, ainda não se pode, com efeito, optar por um formato em detrimento do outro, em virtude de determinadas inseguranças que, ainda, na prática, são passíveis de ocorrer.

[...] De fato, como assinalou Monteleone, não se provou até hoje de forma teórica ou mesmo empírica que o grau de justiça de uma sentença seja diretamente proporcional à soma dos poderes e atribuições do juiz, nem que as partes atuem ou se defendam em juízo movidas apenas pelo desejo de injustiça $[. . .]^{14}$

É de se notar, em virtude disto, que uma saída, para qualquer um dos módulos (ativista ou individualista) as a serem optados, é a tão buscada decisão fundamentada. Esta decisão fundamentada, apenas pode, com efeito, receber tal rótulo, na medida em que atende os aspectos políticos que a Constituição Federal preconizou. Entretanto, questão tortuosa é delimitar, o que, com efeito, seria fundamentar uma decisão, substancialmente em virtude da subjetividade do tema, e, igualmente, dos critérios de valoração que permeiam este particular.

Dentre o aspecto processual desta fundamentação, é invariável inferir principalmente no que diz respeito à temática das provas, objeto de nosso estudo neste momento. Verificamos, sob este enforque que, analisando-as (provas) sob a perspectiva do modelo processual contemporâneo (como tema de direito processual), onde a figura do magistrado é ativa, e buscase os critério subjetivos que ajudaram a fomentar a lide, não apenas os critérios relativos à como se provar o direito para a obtenção de determinado bem jurídico, possuem relevância, como veremos adiante, mas serão a motivação de refletirmos sobre o modo de aplicação da Súmula no 7, do Superior Tribunal de Justiça.

${ }^{14}$ PEÑA, E. C. S. Poderes e atribuições do juiz. São Paulo. Saraiva, 2014. P. 109. 
PAGANI, Vitor Augusto Gaioski e BELLOTTO, Caio Cezar. Amplificação do conceito de prova como corolário ao princípio do contraditório: revisitando a súmula no 7 do superior tribunal de justiça. Revista Eletrônica Direito e Política, Programa de Pós-Graduação Stricto Sensu em Ciência Jurídica da UNIVALI, Itajaí, v.10, n.3, 2ㅇ quadrimestre de 2015. Disponível em: www.univali.br/direitoepolitica ISSN 1980-7791.

\section{A BARREIRA DA SÚMULA 7 DO STJ}

A famigerada Súmula no 7 , do Superior Tribunal de Justiça dispõe que: $A$ pretensão de simples reexame de prova não enseja Recurso Especial. Tal disposição, julgada em 28/06/1990, e publicada em 03/07/1990, indubitavelmente, consolidou o início de uma jurisprudência defensiva no seio desta Egrégia Corte.

Inicialmente, cumpre ponderar que de uma passar de olhos nas decisões que ensejaram a formação desta súmula, inicialmente, observamos que ${ }^{15}$, nos termos de seu voto, sustenta-se que "Descabe o recurso especial para simples reexame de provas, ainda que interposto sob invocação de suposta infringência de norma processual (Súmula 279/STF)". De outro lado, outro decisum "formador da súmula" ${ }^{16}$, pondera que nos autos já foram demonstrados a suficiência probatória na instrução do julgamento da causa, o que não acarretaria cerceamento de defesa.

Outrossim, o REsp no 982-RJ, nos termos da reprodução de sua ementa, exterioriza que: "Quando órgãos judicantes decidem diversamente a mesma espécie, porque um deles considera bastante a prova e o outro insuficiente, tal conduta não se confunde como critério legal de valorização da prova".

15 PROCESSUAL CIVIL. RECURSO ESPECIAL. MATERIA DE FATO. DESCABE O REEXAME DE PROVA NO AMBITO DO RECURSO ESPECIAL. AGRAVO REGIMENTAL DESPROVIDO. (BRASIL. SUPERIOR TRIBUNAL DE JUSTIÇA. AgRg no Ag: 499 SP 1989/0010146-3, Relator: Ministro BARROS MONTEIRO, Data de Julgamento: 24/10/1989, T4 - QUARTA TURMA, Data de Publicação: DJ 20.11.1989 p. 17295 RSTJ vol. 16 p. 162).

16 EMBARGOS DE TERCEIRO. NECESSIDADE DE AUDIENCIA. JULGAMENTO ANTECIPADO DA LIDE. CERCEAMENTO DE DEFESA. I - DEMONSTRADO NOS AUTOS QUE A PROVA NELE CONTIDA JA ERA SUFICIENTE PARA PROFERIR A DECISÃO, A FALTA DE AUDIENCIA DE INSTRUÇÃO E JULGAMENTO NÃO IMPLICA EM CERCEAMENTO DE DEFESA. II - O RECURSO ESPECIAL NÃO SE PRESTA PARA O REEXAME DA PROVA (SUMULA 279). III - INUMEROS DISPOSITIVOS LEGAIS NÃO PREQUESTIONADOS (SUMULA N. 282). DISSIDIO JURISPRUDENCIAL QUE NÃO ATENDE AOS REQUISITOS DA SUMULA 291 C/C O ART. 255, PARÁGRAFO ÚNICO, DO RI/S.T.J. IV RECURSO ESPECIAL NÃO CONHECIDO. (BRASIL. SUPERIOR TRIBUNAL DE JUSTIÇA. REsp: 674 MS 1989/0009951-5, Relator: Ministro FONTES DE ALENCAR, Data de Julgamento: 12/12/1989, T4 - QUARTA TURMA, Data de Publicação: DJ 19.03.1990 p. 1948 RSTJ vol. 16 p. 191) 
PAGANI, Vitor Augusto Gaioski e BELLOTTO, Caio Cezar. Amplificação do conceito de prova como corolário ao princípio do contraditório: revisitando a súmula no 7 do superior tribunal de justiça. Revista Eletrônica Direito e Política, Programa de Pós-Graduação Stricto Sensu em Ciência Jurídica da UNIVALI, Itajaí, v.10, n.3, 2ㅇ quadrimestre de 2015. Disponível em: www.univali.br/direitoepolitica ISSN 1980-7791.

É deveras perceptível que muito já se modificou na estrutura do Colendo Superior Tribunal de Justiça ao longo dos últimos anos, todavia, mesmo malgrado as muitas mudanças, bem como se inferiu acima, no sentido da própria mais do que evidente transformação na concepção de processo civil a caminho de uma consonância cada vez maior com a Constituição Federal, por seu turno, a afamada súmula objeto de análise, continuo impávida.

O presente estudo não possui o mote de desconstituir a impossibilidade de reanálise das provas em sede de Superior Tribunal de Justiça. Sem dúvida, a Constituição Federal é cristalina em delimitar as hipóteses de interposição de Recurso Especial. Ocorre, entrementes, que alguns nuances típicos do processo civil, como, por exemplo, a busca por uma tutela jurisdicional efetiva, segundo já dito no início do trabalho, não passa desapercebida pela Magna Carta e, derivando deste particular, o conceito de prova para a Súmula no 7 , sem embargo, é totalmente defasada.

Veja-se, por exemplo, que a jurisprudência continua a tratar da matéria de prova essencialmente como se estivesse a falar sobre a relação de fatos. Registra-se novamente que, não são todas as vezes que a prova irá se confundir com os fatos. Prova é intimamente ligada a instrução processual, a qual, por seu turno, está proximamente conexa à uma decisão judicial fundamentada em um aspecto de justiça. Relegar a matéria probatória como simples análise dos fatos é imaginar, com o devido acato, que os litigantes não foram frutos de um meio predecessor, como se estivessem sido recém concebidos e habitasse o Jardim do Éden.

Por isto, seria salutar que o Superior Tribunal de Justiça aprimorasse o conceito de "reexame de prova" para fins de analisar isto sob a égide da aplicação, ou não, de sua Súmula no 7 . Vejamos no aresto abaixo, que, ainda que timidamente, este respeitável Areópago acaba modulando os 
PAGANI, Vitor Augusto Gaioski e BELLOTTO, Caio Cezar. Amplificação do conceito de prova como corolário ao princípio do contraditório: revisitando a súmula no 7 do superior tribunal de justiça. Revista Eletrônica Direito e Política, Programa de Pós-Graduação Stricto Sensu em Ciência Jurídica da UNIVALI, Itajaí, v.10, n.3, 2ㅇ quadrimestre de 2015. Disponível em: www.univali.br/direitoepolitica ISSN 1980-7791.

efeitos do que se entende por "prova", nesta recente decisão, reconhecendo algumas diferenças no condão da instrução processual.

PROCESSUAL CIVIL. FORNECIMENTO DE ENERGIA ELÉTRICA. INVERSÃO DO ÔNUS DA PROVA. REGRA DE INSTRUÇÃO. EXAME ANTERIOR À PROLAÇÃO DA SENTENÇA. PRECEDENTES DO STJ. 1.

A jurisprudência desta Corte é no sentido de que a inversão do ônus da prova prevista no art. $6^{\circ}$, VIII, do CDC, é regra de instrução e não regra de julgamento, sendo que a decisão que a determinar deve - preferencialmente - ocorrer durante 0 saneamento do processo ou - quando proferida em momento posterior - garantir a parte a quem incumbia esse ônus a oportunidade de apresentar suas provas. Precedentes: REsp 1395254/SC, Rel. Ministra NANCY ANDRIGHI, TERCEIRA TURMA, julgado em 15/10/2013, DJe 29/11/2013; EREsp 422.778/SP, Rel. Ministro JOÃO OTÁVIO DE NORONHA, Rel. p/ Acórdão Ministra MARIA ISABEL GALLOTTI, SEGUNDA SEÇÃO, julgado em 29/02/2012, DJe 21/06/2012. 2. Agravo regimental não provido. (grifo nosso) ${ }^{17}$

Neste sentido, é patente vislumbrar que, mesmo que de forma comedida, - Superior Tribunal de Justiça passou a entender que a questão de inversão do ônus da prova é uma "regra de instrução", não sendo, pois, "regra de julgamento". Desta maneira, parece-nos substancial refletir sobre as palavras de Rogéria Dotti Doria.

[...] Outro ponto que merece ser esclarecido liga-se à natureza das regras que fixam a distribuição do ônus probatório entre as partes. Discute-se se corresponde esta disciplina a uma regra de procedimento - indicando quem deve provar o que, no processo ou uma regra de julgamento - designando como o magistrado deve julgar diante da falta de prova sobre certo ponto controvertido do processo. Embora conduzam a consequências similares, cada qual destas orientações defende distinta opinião em relação à função e à ocasião em que esta regra tem aplicação. $[\ldots]^{18}$

Por isto, não é exagero entender que ao mesmo tempo em que o Egrégio Superior Tribunal de Justiça entende ser a matéria de prova uma questão praticamente idêntica a revisitação dos fatos (segundo se tem entendido

17 BRASIL. SUPERIOR TRIBUNAL DE JUSTIÇA. AgRg no REsp 1450473/SC, Rel. Ministro MAURO CAMPBELL MARQUES, SEGUNDA TURMA, julgado em 23/09/2014, DJe 30/09/2014.

18 DORIA, R. D. Provas: aspectos atuais do direito probatório. coord. Daniel Amorim Assumpção Neves. Rio de Janeiro. Forense. São Paulo, Método, 2009. P. 331. 
PAGANI, Vitor Augusto Gaioski e BELLOTTO, Caio Cezar. Amplificação do conceito de prova como corolário ao princípio do contraditório: revisitando a súmula no 7 do superior tribunal de justiça. Revista Eletrônica Direito e Política, Programa de Pós-Graduação Stricto Sensu em Ciência Jurídica da UNIVALI, Itajaí, v.10, n.3, 2ㅇ quadrimestre de 2015. Disponível em: www.univali.br/direitoepolitica ISSN 1980-7791.

pela aplicação da Súmula no 7, e, o que teria severa implicação em reconhecer que o direito probatório é um direito material, e não processual), ao mesmo tempo tem demonstrado que a prova (ou o modelo pelo qual irá optar pela sua constituição), de fato, influi significativamente na decisão que será proferida.

Sobre esta questão, vejamos a lição de Artur T. Carpes.

[...] A justificativa de que "o ônus da prova é regra de julgamento" não vinga, pois padece de evidente vício dogmático: ao deixar de considerar o problema enquanto inserido em uma complexa sistemática, na qual avultam as múltiplas implicações no processo com o direito constitucional, as respectivas garantias nele previstas e os valores a ele subjacentes, enfoca-se apena um lado da moeda - o da técnica procedimental - olvidando-se do outro, inerente à participação, ao contraditório, isto é, da construção dialógica da decisão justa. $[\ldots]^{19}$

A visão processualista da prova, sob a determinação da variação de seu ônus como "medida de instrução", sem margem à erros, é inversamente proporcional ao conteúdo da Súmula n 7. Explico. Não é possível verificar a distribuição do ônus da prova, o qual cominará para a designação das responsabilidades de defesa (contraditório), apenas pelo contexto fático. O contexto fático, sim, não pode ser detalhado, nem, outrossim, discutido em sede de Recurso Especial.

Vejamos que, com propriedade, Luiz Eduardo Boaventura Pacífico pondera, ao nosso ver, esta possibilidade (ou, em uma interpretação mais intensa, um dever) de dissociação entre os "fatos discutidos no âmbito do processo" e o "contexto fático da realidade".

[...] Os fatos, portanto, só podem ser qualificados no contexto de uma relação, de modo que não se afigura possível estabelecer os ônus probatórios apenas e tão somente com base na divisão dos fatos nas referidas categorias. É preciso, também, haver critérios a partir dos quais seja possível classificar, em uma caso concreto, os fatos relevantes do processo naquelas categorias. $[\ldots]^{20}$

${ }^{19}$ CARPES, A. T. Prova judiciária: estudos sobre o novo direito probatório. coord. Danilo Knijnik. Porto Alegre. Livraria do Advogado, 2007. P. 41.

20 PACÍfICO, L. E. B. O ônus da prova. 2. ed. São Paulo. Revista dos Tribunais, 2011. P. 206. 
PAGANI, Vitor Augusto Gaioski e BELLOTTO, Caio Cezar. Amplificação do conceito de prova como corolário ao princípio do contraditório: revisitando a súmula no 7 do superior tribunal de justiça. Revista Eletrônica Direito e Política, Programa de Pós-Graduação Stricto Sensu em Ciência Jurídica da UNIVALI, Itajaí, v.10, n.3, 2ㅇ quadrimestre de 2015. Disponível em: www.univali.br/direitoepolitica ISSN 1980-7791.

Observe que o exame de prova, aparentemente, como já mencionado anteriormente, não trata apenas no reexame dos fatos, o que, unicamente é vedado por conta da Súmula no 7. Quer nos parecer, por esta forma que, ou existe um equívoco na interpretação da dita súmula, ou, de outro modo, a mesma, hodiernamente, assumiu uma postura similar a já reconhecida "jurisprudência defensiva".

Muito embora seja mais comum analisarmos, e, igualmente, estudarmos, a distinção entre as normas, operando, pois, suas respectivas qualificações, é cabal que seja analisada, principalmente para fins de interposição de Recurso Especial, uma temática que, mesmo malgrado já possua estudos a respeito, ainda é tratada com timidez em nossa doutrina jurídica.

Este tópico, em verdade, é a chamada de qualificação jurídica dos fatos. No mesmo patamar de investigação, é de bom alvedrio lembrar, mesmo muito embora não seja o tema central deste estudo, que a teoria do fato jurídico também exerce fundamental pressão sobre a análise dos fatos. Há mais de uma década, o Egrégio Superior Tribunal de Justiça já caminha em boas estradas, recepcionando tal teoria, senão vejamos.

ADMINISTRATIVO. RECURSO ESPECIAL. ARTIGO 105, INCISO III, A E C, DA CONSTITUIÇÃO DA REPÚBLICA. REGISTRO NO CREA. OBRIGATORIEDADE. ARTIGOS 59 e 60 DA LEI 5.194/66 E 10 DA LEI $6.839 / 80$. PRECEDENTES. QUALIFICAÇÃO JURÍDICA DOS FATOS. In casu, a empresa recorrida é fabricante de máquinas e equipamentos para a indústria têxtil, atividade que requer conhecimentos técnicos privativos de engenheiros especializados, responsáveis por desenvolver e projetar os produtos, além de acompanhar sua fabricação. Dessarte, à luz do que dispõem os artigos 59 e 60 da Lei n. 5.194/66 e $1^{\circ}$ da Lei n. 6.839/80, para desenvolver sua atividade industrial e comercial, torna-se obrigatório o registro da recorrida no órgão de fiscalização profissional, qual seja, o Conselho Regional de Engenharia e Arquitetura de Santa Catarina - CREA/SC. A hipótese vertente não trata de matéria puramente de fato. Em verdade, cuida-se de 
PAGANI, Vitor Augusto Gaioski e BELLOTTO, Caio Cezar. Amplificação do conceito de prova como corolário ao princípio do contraditório: revisitando a súmula no 7 do superior tribunal de justiça. Revista Eletrônica Direito e Política, Programa de Pós-Graduação Stricto Sensu em Ciência Jurídica da UNIVALI, Itajaí, v.10, n.3, 2ㅇ quadrimestre de 2015. Disponível em: www.univali.br/direitoepolitica ISSN 1980-7791.

qualificação jurídica dos fatos, que se não confunde com matéria de fato. Recurso especial provido(grifo nosso). ${ }^{21}$

Necessária se faz uma pausa para refletirmos, com o fito de estabelecer um conclusão sobre este período, nos ensinamentos de José Miguel Garcia Medina.

[...] Há violação à ordem jurídica tanto ao se aplicar o direito de modo equivocado quanto ao se conceber erroneamente um fato sobre o qual incidia a lei correta. Tanto num quanto noutro caso, há aplicação incorreta da lei. Identificando-se o fato de modo impreciso, fatalmente se aplicará a lei também de modo impreciso, pois se aplicará a lei errada, ou seja, a lei inaplicável, à situação, por tratar-se de hipótese diversa da prevista pela lei. $[\ldots]^{22}$

Veja-se, contudo, que não se está procurando inferir que toda e qualquer matéria se qualificaria naquilo que denomina de qualificação jurídica dos fatos, principalmente se nos dermos a oportunidade de um rápido passar de olhos pela jurisprudência recente desta respeitável corte ora em análise.

PROCESSUAL CIVIL. EMBARGOS DE DECLARAÇÃO NO RECURSO ESPECIAL. AUSÊNCIA DOS VÍCIOS DO ART. 535 DO CPC. EFEITOS INFRINGENTES. DESCABIMENTO. PREQUESTIONAMENTO DE MATÉRIA CONSTITUCIONAL. IMPOSSIBILIDADE. EMBARGOS PARCIALMENTE ACOLHIDOS NO TOCANTE À CONTRADIÇÃO NA ANÁLISE DOS ARTS. 535 E 333, INCISO I, DO CPC. 1. Os embargos de declaração não se prestam à modificação de julgado baseado no mero inconformismo da embargante, que repisa os argumentos anteriormente levantados e não acolhidos, circunstância que não indica a existência de omissão, contradição ou obscuridade do julgado. 2. No presente caso, a matéria referente à ausência de comprovação dos fatos constitutivos do direito do autor (art. $333, \mathrm{I}$, do CPC) demanda a análise da matéria probatória (Súmula $7 / S T J$ ). Precedentes. 3. Ao Superior Tribunal de Justiça não é permitido adentrar na competência do Supremo Tribunal Federal, sequer para prequestionar matéria constitucional suscitada em sede de embargos de declaração, sob pena de violar a rígida distribuição de competência recursal disposta na Constituição Federal. 4.

${ }^{21}$ BRASIL. SUPERIOR TRIBUNAL DE JUSTIÇA. REsp: 171219 SC 1998/0025906-6, Relator: Ministro FRANCIULLI NETTO, Data de Julgamento: 12/03/2002, T2 - SEGUNDA TURMA, Data de Publicação: DJ 01.07.2002 p. 274 RSTJ vol. 159 p. 225.

22 MEDINA, J. M. G. O prequestionamento nos recurso extraordinário e especial. 2. ed., São Paulo, Revista dos Tribunais, 1999. P. 306. 
PAGANI, Vitor Augusto Gaioski e BELLOTTO, Caio Cezar. Amplificação do conceito de prova como corolário ao princípio do contraditório: revisitando a súmula no 7 do superior tribunal de justiça. Revista Eletrônica Direito e Política, Programa de Pós-Graduação Stricto Sensu em Ciência Jurídica da UNIVALI, Itajaí, v.10, n.3, 2ㅇ quadrimestre de 2015. Disponível em: www.univali.br/direitoepolitica ISSN 1980-7791.

Embargos de declaração parcialmente acolhidos, sem efeitos infringentes. (grifo nosso) ${ }^{23}$

Partindo-se desta premissa, podemos verificar, nas últimas décadas, que o Superior Tribunal de Justiça, com efeito, acabou, mesmo que indiretamente, ponderando sobre a modificação do ônus da prova.

Neste espaço, convém analisar os ensinamentos, dos quais, respeitosamente, discordamos, do professor Paulo Rogério Zaneti, os quais, mesmo a despeito de serem indiscutivelmente fundamentados, pecam no sentido de equiparar a matéria probatória, como já dissemos, sempre como um sinônimo para a questão fática.

[...] Dissemos que pela teoria da carga dinâmica da prova atribuise o ônus probatório, mediante a presença de determinadas circunstâncias de fato, ao litigante que tiver melhores condições ou facilidades de produzir a prova em juízo.

Nesse sentido, para afastar a aplicação da regra geral de distribuição do ônus da prova contida no art. 333 do CPC o magistrado deverá fazer uma análise, detida e criteriosa, dos fatos e circunstâncias que impedem uma das partes de se desincumbir de seu ônus probatório em determinado caso concreto, ou, ainda, que causem a um dos litigantes extrema dificuldade probatória. Note-se que essa análise do caso concreto, feita pelo magistrado, é estritamente fática.

Portanto, parece-nos que a Súmula 7 do STJ se apresentaria como óbice intransponível a eventual recurso especial interposto pela aplicação da teoria da carga dinâmica da prova por tribunal estadual ou federal, na medida em que para proferir eventual decisão a respeito o STJ haveria de adentrar, necessariamente, o reexame dos fatos que levaram à aplicação dessa teoria pelo tribunal local - o que não lhe é permitido. $[\ldots]^{24}$

Conforme constatamos anteriormente, não serão todas as vezes que fatos confundir-se-ão com provas. Analisar o caso concreto, nos termos do supramencionado, nem sempre será óbice para a interposição de Recurso Especial, haja vista a necessidade de ponderação sobre os efeitos constantes da Súmula no 7 desta Egrégio Corte.

23 BRASIL. SUPERIOR TRIBUNAL DE JUSTIÇA. EDCl no REsp 1374284/MG, Rel. Ministro LUIS FELIPE SALOMÃO, SEGUNDA SEÇÃO, julgado em 24/09/2014, DJe 30/09/2014

${ }^{24}$ ZANETI. P. R.. Flexibilização das regras sobre o ônus da prova. São Paulo. Malheiros, 2011. P. 168-9. 
PAGANI, Vitor Augusto Gaioski e BELLOTTO, Caio Cezar. Amplificação do conceito de prova como corolário ao princípio do contraditório: revisitando a súmula no 7 do superior tribunal de justiça. Revista Eletrônica Direito e Política, Programa de Pós-Graduação Stricto Sensu em Ciência Jurídica da UNIVALI, Itajaí, v.10, n.3, 2ㅇ quadrimestre de 2015. Disponível em: www.univali.br/direitoepolitica ISSN 1980-7791.

\section{CONSIDERAÇÕES FINAIS}

Mesmo a despeito de o tema "prova", em um primeiro momento, parecer um tema pouco discutível, uma vez que, na grande maioria das vezes, o mesmo apenas se reverteria à análise dos fatos, em muitas circunstâncias podemos admitir que tal assertiva se demonstra inegavelmente equivocada, substancialmente em virtude de que, numa concepção atualizada de prova, o mesmo possui amplificado seu condão de alcance, elevando significativamente no decorrer da instrução processual.

Neste sentido, é curial que a aplicação da Súmula no 7 , do Superior Tribunal de Justiça seja, outrossim, analisada com outros olhos, justamente em vista de não se pode olvidar, pois, neste contexto, que a ampliação do conceito de prova se demonstra curial a permitir uma instrução processual adequada e, nesta senda, permitir um efetivo contraditório.

Segundo procurou-se demonstrar desde as decisões que fundamentaram a existência da Súmula no 7 , até a mais recentes decisões do Egrégio Superior Tribunal de Justiça acerca da aplicação da súmula supramencionada, verificou-se uma modificação no entendimento da mesma, uma vez que passou-se a analisar, com fulcro em uma doutrina robusta sobre o tema, por exemplo, a inversão do ônus da prova como matéria de instrução, não sendo, portanto, uma regra de julgamento, o que vedaria, inegavelmente, seu alcance ao areópago supramencionado, em sede de Recurso Especial.

Com o mote de corroborar as fundamentações acima, demonstrou-se que, neste particular, uma papel fundamental fora exercido, novamente, pela doutrina jurídica, e, igualmente, recepcionado pelo Colendo Superior Tribunal de Justiça, no sentido de reconhecer que a qualificação jurídica 
PAGANI, Vitor Augusto Gaioski e BELLOTTO, Caio Cezar. Amplificação do conceito de prova como corolário ao princípio do contraditório: revisitando a súmula no 7 do superior tribunal de justiça. Revista Eletrônica Direito e Política, Programa de Pós-Graduação Stricto Sensu em Ciência Jurídica da UNIVALI, Itajaí, v.10, n.3, 2ㅇ quadrimestre de 2015. Disponível em: www.univali.br/direitoepolitica ISSN 1980-7791.

dos fatos, por seu turno, não vem a ser confundida com matérias de fato propriamente ditas.

Sendo assim, é inerente analisar que, desde seu nascimento, a Súmula no 7 , sofreu uma substancial mitigação em seu bojo, fatalmente em virtude de que o conceito de prova, conforme visto de forma sumária na elaboração deste estudo, fora modificada significativamente.

Entrementes, nos termos, outrossim, sustentados, resta imperioso inferir que o objeto do trabalho não busca a diminuição completa da Súmula no 7, uma vez que o comando autorizadores da mesma encontram-se esculpido no corpo da Constituição Federal.

Esta mesma Constituição Federal, ao ser encarada por uma leitura mais atenta, e, neste sentido, deixada de ser constituída em nosso ordenamento jurídico com um simples condão cabalmente programático, conforme se extrai da doutrina do neoconstitucionalismo, formadora do neoprocessualismo, não só permitiu a generalização da amplificação do conceito de prova sob a égide da verificação de uma hígida instrução processual, como possibilita entender que a simples reanálise dos fatos deve ser coibida pelo Superior Tribunal de Justiça.

\section{REFERÊNCIAS DAS FONTES CITADAS}

BRASIL. SUPERIOR TRIBUNAL DE JUSTIÇA. REsP: 674 MS 1989/0009951-5, Relator: Ministro FONTES DE ALENCAR, Data de Julgamento: 12/12/1989, T4 - QUARTA TURMA, Data de Publicação: DJ 19.03.1990. p. 1948 RSTJ vol. 16 p. 191

BRASIL. SUPERIOR TRIBUNAL DE JUSTIÇA. AgRg no Ag: 499 SP 1989/0010146-3, Relator: Ministro BARROS MONTEIRO, Data de Julgamento: 24/10/1989, T4 - QUARTA TURMA, Data de Publicação: DJ 20.11.1989. p. 17295 RSTJ vol. 16 p. 162 
PAGANI, Vitor Augusto Gaioski e BELLOTTO, Caio Cezar. Amplificação do conceito de prova como corolário ao princípio do contraditório: revisitando a súmula no 7 do superior tribunal de justiça. Revista Eletrônica Direito e Política, Programa de Pós-Graduação Stricto Sensu em Ciência Jurídica da UNIVALI, Itajaí, v.10, n.3, 2ㅇ quadrimestre de 2015. Disponível em: www.univali.br/direitoepolitica ISSN 1980-7791.

BRASIL. SUPERIOR TRIBUNAL DE JUSTIÇA. AgRg no REsp 1450473/SC, Rel. Ministro MAURO CAMPBELL MARQUES, SEGUNDA TURMA, julgado em 23/09/2014, DJe 30/09/2014.

BRASIL. SUPERIOR TRIBUNAL DE JUSTIÇA. EDcl no REsp 1374284/MG, Rel. Ministro LUIS FELIPE SALOMÃO, SEGUNDA SEÇÃO, julgado em 24/09/2014, DJe 30/09/2014.

BRASIL. SUPERIOR TRIBUNAL DE JUSTIÇA. REsP: 171219 SC 1998/0025906-6, Relator: Ministro FRANCIULLI NETTO, Data de Julgamento: 12/03/2002, T2 - SEGUNDA TURMA, Data de Publicação: DJ 01.07.2002. p. 274 RSTJ vol. 159 p. 225.

CAMBI, E.. Neoconstitucionalismo e neoprocessualismo: direitos fundamentais, políticas públicas e protagonismo judiciário. 2. ed. São Paulo. Revista dos Tribunais, 2011.

CARPES, A. T. Prova judiciária: estudos sobre o novo direito probatório. coord. Danilo Knijnik. Porto Alegre. Livraria do Advogado, 2007.

DORIA, R. D. Provas: aspectos atuais do direito probatório. coord. Daniel Amorim Assumpção Neves. Rio de Janeiro. Forense. São Paulo, Método, 2009.

FAZZALARI, E. Instituições de Direito Processual. trad. Elaine Nassif. Campinas: Bookseller, 2006.

GRINOVER, A. P. O processo em evolução. 2. ed. Rio de Janeiro. Forense, 1998.

MACIEL JUNIOR, J. B. Aplicabilidade do princípio do contraditório nas relações particulares. São Paulo. Saraiva, 2009.

MEDINA, J. M. G. O prequestionamento nos recurso extraordinário e especial. 2. ed., São Paulo, Revista dos Tribunais, 1999.

LEITE, G. Apontamentos sobre a Teoria Geral da Prova. Revista Síntese Direito Civil e Processual Civil. v.12, n.84, jul/ago. 2013.

LOPES, M. E. d. C.. Princípios processuais civis na Constituição. coord: Maria Elizabeth de Castro Lopes e Olavo de Oliveira Neto. Rio de Janeiro. Elsevier, 2008.

PACÍfICO, L. E. B. O ônus da prova. 2. ed. São Paulo. Revista dos Tribunais, 2011.

PEÑA, E. C. S. Poderes e atribuições do juiz. São Paulo. Saraiva, 2014.

RANGEL, R. M. d. F. O ónus da prova no processo civil. Coimbra, Almedina. 2006.

ROSITO, F. Direito probatório: as máximas de experiência em juízo. Porto Alegre. Livraria do Advogado, 2007. 
PAGANI, Vitor Augusto Gaioski e BELLOTTO, Caio Cezar. Amplificação do conceito de prova como corolário ao princípio do contraditório: revisitando a súmula no 7 do superior tribunal de justiça. Revista Eletrônica Direito e Política, Programa de Pós-Graduação Stricto Sensu em Ciência Jurídica da UNIVALI, Itajaí, v.10, n.3, 2ㅇ quadrimestre de 2015. Disponível em: www.univali.br/direitoepolitica ISSN 1980-7791.

SILVA, V. A. d. A constitucionalização do direito: os direitos fundamentais nas relações entre particulares. São Paulo. Malheiros, 2005.

TARUFFO, M. Processo civil comparado: ensaios. apres. org. e trad. Daniel Mitidiero. São Paulo. Marcial Pons, 2013.

TEIXEIRA, W. d. B. L. A Natureza Jurídica das Normas sobre Provas. Revista Jurídica: órgão nacional de doutrina, jurisprudência, legislação e crítica judiciária. Ano 61, no 430, Agosto, 2013.

ZANETI. P. R.. Flexibilização das regras sobre o ônus da prova. São Paulo. Malheiros, 2011.

Submetido em: Maio/2015

Aprovado em: Julho/2015 